Check for updates

Cite this: RSC Adv., 2017, 7, 22112

Received 11th March 2017

Accepted 5th April 2017

DOI: $10.1039 / \mathrm{c} 7 \mathrm{ra02950k}$

rsc.li/rsc-advances

\section{A macro-porous graphene oxide-based membrane as a separator with enhanced thermal stability for high-safety lithium-ion batteries $\uparrow$}

\author{
Haiyang Liao, (DD ${ }^{a}$ Haiyan Zhang, (D) *ab Gai Qin, ${ }^{a}$ Zhenghui Li, ${ }^{\text {ab }}$ Liuqing $\mathrm{Li}^{\mathrm{a}}$ \\ and Haoqun Hong ${ }^{\text {ab }}$
}

To develop a separator with remarkable thermal-resistance for high-safety lithium-ion (Li-ion) batteries, a graphene oxide (GO)-grafted hyper-branched polyether (GO-g-HBPE) macro-porous membrane without any polymer binder was designed and prepared using polystyrene (PS) nanoparticles as hard templates. GO (inorganic part) provides the membrane-formation ability for GO-g-HBPE separator and HBPE (polymer part) imparts excellent affinity with the liquid electrolyte $158 \%$ for liquid electrolyte uptake). The GO-g-HBPE membrane, serving as a separator for the batteries, exhibited robust thermal dimensional stability with no dimensional changes at $200{ }^{\circ} \mathrm{C}$ for $0.5 \mathrm{~h}$. Moreover, it shows a better electrochemical performance (cycle performance and rate capability) than a commercialized PP separator, implying a promising potential for application in high-safety and high-power Li-ion batteries.

\section{Introduction}

Fossil fuels as an energy source have been widely exploited and applied in energy devices in past decades. However, because of their non-renewable nature, these energy sources are becoming scarce and their low energy transformation efficiency severely restricts applications in high-power and high-energy density devices..$^{1-5}$ The research and development of green, clean and sustainable energy systems has become the main focus of the world. ${ }^{6}$ Li-ion batteries due to their high energy density, long cycle life and environmental friendliness have been identified as a potential choice to substitute fossil fuels. ${ }^{7,8}$ Much research has been conducted on Li-ion batteries recently, and their applications have been expanded to the field of electric vehicles and electric power tools. ${ }^{9}$ Unfortunately, the safety aspect of the present Li-ion batteries is still the main restraining factor in the development of energy storage devices. The separator plays a critical role in preventing the physical contact between positive and negative electrodes, which further triggers shortcircuiting and thermal runaway. ${ }^{10}$ However, commercial polyolefin separators (polyethylene (PE) and polypropylene (PP)), suffer from a low melting temperature $\left(135^{\circ} \mathrm{C}, 160{ }^{\circ} \mathrm{C}\right.$; respectively); once the internal temperature in the batteries rises up above the melting temperature of these separators, an internal

${ }^{a}$ School of Materials and Energy, Guangdong University of Technology, Guangzhou 510006, China. E-mail: hyzhang@gdut.edu.cn

${ }^{b}$ Guangdong Provincial Key Laboratory of Functional Soft Condensed Matter, Guangdong University of Technology, Guangzhou 510006, China

$\dagger$ Electronic supplementary information (ESI) available. See DOI: $10.1039 / \mathrm{c} 7 \mathrm{ra} 02950 \mathrm{k}$ short-circuit can occur, resulting in great shrinkage of the separator. ${ }^{11,12}$ As such, Li-ion batteries with high thermal stability are urgently required.

A series of investigations has been carried out to improve the thermal-resistance of the polyolefin-based separators. For example, coating inorganic nanoparticles and organic polymers on these separators, as dimensional-resistance covering layer, have attracted considerable attention due to their robust heat stability and relatively high melting temperature. ${ }^{13}$ Recently, Shin et al. reported core-shell poly(lithium 4-styrenesulfonate) (a) $\mathrm{SiO}_{2}$ nanoparticles decorated on the both sides of PP separator via a casting method..$^{14}$ This core-shell $\mathrm{SiO}_{2}$-modificated PP separator significantly reduced the thermal shrinkage and electrochemical performance. Furthermore, Song et al. ${ }^{15}$ reviewed co-polyimide-coated PE separator, which exhibited noticeable mechanical strength and excellent thermalresistance. Although the coating method is economical, efficient and an easily controlled process, it fails to provide a longterm protective effect, because it is easily washed off by solvents. ${ }^{16-18}$ Moreover, the inorganic nanoparticles suspended in organic binder can easily form an aggregate or agglomerates, further resulting in non-uniform pores distributed in the separator, thereby affecting the ion transportability. ${ }^{19}$ In the case of organic polymer coating, toxic solvents retained from the preparation stage may significant reduce the electrochemical performance of the separator. ${ }^{20}$ Another approach uses non-woven or inorganic separators to take the place of polyolefin based separators. Raja $e t$ al. ${ }^{21}$ reported a thin, flexible and thermally stable ceramic $\left(\mathrm{MgAl}_{2} \mathrm{O}_{4}\right)$ separator for Li-ion batteries, and Jung et al. ${ }^{22}$ developed ceramic $\left(\mathrm{Li}_{7} \mathrm{La}_{3} \mathrm{Zr}_{2} \mathrm{O}_{12}\right)$ separators based on $\mathrm{Li}^{+}$-conducting inorganic electrolyte. 
Despite the high safety obtained by these separators, the process of membrane formation still requires the use of organic polymeric binders; these organic polymeric binders are not thermally stable as the ceramic, and hence are fragile under relatively high temperatures. For this reason, a non-polymeric binder membrane with noticeable heat-resistance as a separator for Li-ion batteries is of great significance.

GO with multi-oxygen groups (hydroxyl, epoxy, carbonyl, ether and carboxyl) is oxidized from natural graphite and these oxygen groups impede electron conducting in the skeleton of GO, resulting in high electronic insulation. Moreover, the highly oxidized GO is an easy formation of a non-polymeric binder membrane obtained by the interaction with the oxygen-containing groups. ${ }^{23}$ However, the lactols, epoxy and carbonyl groups in GO are sensitive to electrochemical, resulting in partial reduction under electrochemical processes, which are not desirable for battery operations. To overcome these drawbacks, we grafted HBPE on the GO by polycondensation for improving electrolyte compatibility and reducing the content of the electrochemical and thermal active groups (lactols, epoxy and carbonyl). Subsequently, a macro-porous membrane without any polymer binder was prepared by filtrating and extracting PS nanoparticles in GO- $g$-HBPE matrix. This membrane is the first time to serve as separator for Li-ion batteries, and the results exhibit remarkable thermalresistance and superior electrochemical performance.

\section{Experimental}

\subsection{Materials}

A PP separator (Celgard 2400, porosity: 39\%, $25 \mu \mathrm{m}$ ) in this study was used as a contrast sample. Natural graphite power (30 $\mu \mathrm{m})$ was supplied from Huayuan Chemical Co., Ltd. (Shanghai, China). Furthermore, 1,1,1-tri(hydroxymethyl)propane (TMP), glycidol and potassium were provided by Aladdin Industrial Co. (Shanghai, China). Methanol was distilled under vacuum to remove moisture prior to use. Styrene treated by alkaline- $\mathrm{Al}_{2} \mathrm{O}_{3}$ to remove the inhibitor was donated by Damao Chemical Reagent Co., Ltd. (Tianjing, China). Concentrated $\mathrm{H}_{2} \mathrm{SO}_{4}$, $\mathrm{H}_{3} \mathrm{PO}_{4}$, potassium peroxide sulfate (KPS), para-toluenesulfonic acid (PDSA), $N, N$-dimethylformamide (DMF) and toluene were used without any purification, and all the chemical reagents were AR grade. The $\mathrm{LiPF}_{6}$ electrolyte, which contained a potential stabilizer, was dissolved in EC/DEM/EMC in a weight ratio of $1: 1: 1$ and obtained from Zhangjiagang Guotai-Huarong New Chemical Materials Co., Ltd. (Jiangsu, China).

\subsection{Preparation of GO}

GO was prepared using the modified Hummers' method. ${ }^{24}$ Typically, a $9: 1(400 \mathrm{ml}, \mathrm{v} / \mathrm{v})$ mixture of concentrated $\mathrm{H}_{2} \mathrm{SO}_{4} /$ $\mathrm{H}_{3} \mathrm{PO}_{4}$ was added to a reaction bottle, which contained a mixture of nature graphite $(3 \mathrm{~g})$ power and $\mathrm{KMnO}_{4}(18 \mathrm{~g})$. The reaction was performed under $50{ }^{\circ} \mathrm{C}$ with stirring for $12 \mathrm{~h}$. The reaction was then cooled to room temperature and poured into ice water $(400 \mathrm{ml})$ with a $\mathrm{H}_{2} \mathrm{O}_{2}$ solution $(30 \%, 3 \mathrm{ml})$, resulting in a golden yellow suspension. This suspension solution was subsequently filtered through cellulose acetate fibre and washed by deionised (DI) water, $30 \% \mathrm{HCl}$ and ethanol $(\times 2)$ sequentially. The obtained residue was coagulated using $200 \mathrm{ml}$ of ether and filtered over a PVDF membrane with a $0.45 \mu \mathrm{m}$ pore size. The solid product was obtained on the filter and vacuumdried overnight at $45^{\circ} \mathrm{C}$.

\subsection{Synthesis of HBPE}

Anionic ring opening polymerization was introduced to synthesize HBPE. $^{25}$ Briefly, polymerization was carried out in a four-neck bottle equipped with a mechanical stirrer, condenser and dosing pump under an argon atmosphere protection. Moreover, $1.34 \mathrm{~g}$ of TMP was deprotonated with potassium methylate solution ( $30 \mathrm{wt} \%$ ). Furthermore, $50 \mathrm{ml}$ of glycidol was added dropwise at $90{ }^{\circ} \mathrm{C}$ over $12 \mathrm{~h}$. After completion of the reaction, the product was dissolved in methanol and neutralized by adding $1 \mathrm{~mol} \mathrm{l}^{-1} \mathrm{HCl}$ solution. The polymer obtained was precipitated twice from a methanol solution into acetone and subsequently vacuum-dried overnight under $80^{\circ} \mathrm{C}$.

\subsection{Synthesis of PS nanoparticles}

PS nanoparticles were synthesised from soap-free emulsion polymerization. ${ }^{26}$ A $10 \mathrm{ml}$ alkaline- $\mathrm{Al}_{2} \mathrm{O}_{3}$-treated styrene was dispersed in $100 \mathrm{ml}$ DI water with vigorous stirring. Subsequently, $0.1 \mathrm{~g}$ of KPS dissolved in $15 \mathrm{ml}$ DI water was injected into the reactor, and the reaction was performed at $80{ }^{\circ} \mathrm{C}$ under argon protection for $6 \mathrm{~h}$. A milk white solution was obtained.

\subsection{Preparation of GO- $g$-HBPE and macro-porous membrane}

An excess of HBPE ( $10 \mathrm{ml})$ was added to $0.2 \mathrm{~g}$ of $\mathrm{GO}$ power. The mixing was carried out at $125^{\circ} \mathrm{C}$ with $5 \mathrm{mg}$ of PDSA as catalyst for 2 days. After the reaction was complete, $100 \mathrm{ml}$ of DMF was poured into the mixtures to dissolve the excessive HBPE. The solution was then filtered and washed several times with DI water and ethanol until neutral. The obtained solid was vacuum-dried overnight at $55{ }^{\circ} \mathrm{C}$. Furthermore, $0.1 \mathrm{ml}$ of PS nanoparticles colloid ( $30 \mathrm{mg} \mathrm{ml}^{-1}$ ) was added to $2 \mathrm{mg} \mathrm{ml}^{-1}$ of GO- $g$-HBPE solution and sonicated for $5 \mathrm{~h}$. The well-suspended GO- $g$-HBPE/PS solution was filtered to form a membrane, peeled off from the filter and immersed into toluene to extract PS. The resulting membrane was dried at $45^{\circ} \mathrm{C}$. For a systematic comparison with the GO- $g$-HBPE separator, a pure GO separator was prepared without a PS template, and a macroporous GO (MGO) separator was prepared by filtration of the GO dispersion, which contained $0.1 \mathrm{ml}$ PS colloid $\left(30 \mathrm{mg} \mathrm{ml}^{-1}\right)$, and the templates of PS nanoparticles were then extracted. The preparation process of the macro-porous GO- $g$-HBPE membrane is displayed in Fig. 1.

\subsection{Materials characterization}

Scanning electron microscopy (SEM; SN-3400, Hitachi Ltd., Japan) was employed to examine the morphology of the obtained sample and separator. Transmission electron micrographs (TEM) were obtained with a JEM-2010F at an accelerating voltage of $200 \mathrm{kV}$. X-ray photoelectron spectroscopy 


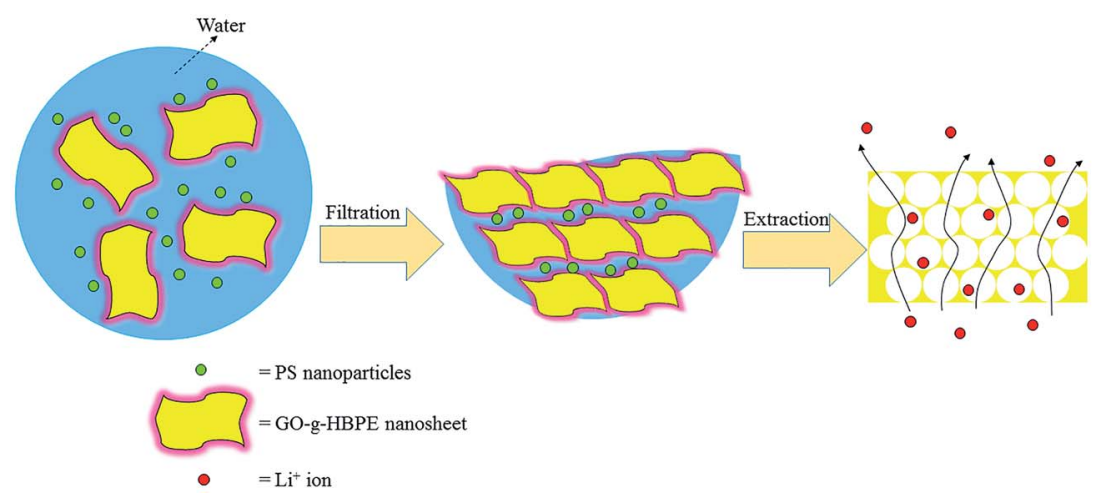

Fig. 1 Schematic showing the preparation of the free-standing GO-g-HBPE macro-porous membrane.

(XPS) was measured on Thermo ESCALAB 250XI spectrometer using $\mathrm{Al} \mathrm{K} \alpha$ radiation $(15 \mathrm{kV}, 150 \mathrm{~W})$. Fourier transform infrared spectroscopy (FTIR) was performed on a Nicolet 6700 spectrometer from 4000 to $500 \mathrm{~cm}^{-1} .{ }^{1} \mathrm{H}$ NMR and ${ }^{13} \mathrm{C}$ NMR spectra were recorded in $\mathrm{d}_{6}$-methanol on a Bruker AV 400 spectrometer at $300 \mathrm{MHz}$. The solid-state NMR (Bruker AV 600 spectrometer, Bruker Co., Germany) was performed to characterize the structure of the samples. X-ray diffraction (XRD, DMAX-Ultima IV, Rigaku Co., Japan) was used to identify the crystal structure of the resulting samples. Raman spectra were recorded using $632.8 \mathrm{~nm}$ laser excitation on LabRAM HR 800 (Horiba Jobin Yvon Co., French). The thermal stability of the separator was evaluated by thermogravimetric analysis (TGA; Q50 TA. Instruments Ltd., USA) heating up to $800{ }^{\circ} \mathrm{C}$ at a heating rate of $10{ }^{\circ} \mathrm{C} \mathrm{min}^{-1}$. The dimensional-resistance of the separator was determined by heating to $200{ }^{\circ} \mathrm{C}$ for $0.5 \mathrm{~h}$. The porosity of the separator was calculated by the following equation: ${ }^{27}$

$$
P \%=\frac{M_{2} / \rho_{1}}{\left(M_{1} / \rho_{1}\right)+\left(M_{2} / \rho_{2}\right)} \times 100
$$

where $P \%, M_{1}, M_{2}, \rho_{1}$ are the porosity, initial weight, weight after soaked $n$-butanol for $1 \mathrm{~h}$ and density of the separator, respectively; $\rho_{2}$ is the density of $n$-butanol. The liquid electrolyte uptake was determined by calculating the difference in the weight before and after soaking in the liquid electrolyte. The equation is as follows:

$$
\eta=W_{2}-W_{1} / W_{1} \times 100
$$

where $W_{1}$ and $W_{2}$ represent the weight of the dry and liquid electrolyte-wetted separator, respectively.

\subsection{Electrochemical measurements}

The electrochemical stability of the separators using the cell type constitution of stainless steel (SS) as the working electrode and $\mathrm{Li}$ as the reference electrode under scanning rate of $5 \mathrm{mV}$ $\mathrm{s}^{-1}$ was investigated on an electrochemical work station (CHI $660 \mathrm{E}, \mathrm{CH}$. Instruments Inc. Shanghai, China). To evaluate ionic conductivity, a blocking-type cell of SS//separator//SS was used to characterize the bulk resistance $\left(R_{\mathrm{b}}\right)$ by A.C. impedance technique. The ionic conductivity was obtained from the following equation: ${ }^{28}$

$$
\sigma=L / R_{\mathrm{b}} A
$$

where the $L$ and $A$ are the thickness and the effective area of the separator, respectively. Chronoamperometry was used to determine the Li ion transference number $\left(t_{+}\right)$under a step potential of $10 \mathrm{mV}$. The electrochemical performance of the cells (charge-discharge capacity, cycling performances and Crate capacity) equipped with the separator, using $\mathrm{LiFePO}_{4}$ and $\mathrm{Li}$ as the cathode and counter electrode, respectively, were determined on the LAND cell testing system (LAND CT2001A, Wuhan, China). The interfacial resistance before and after cycling was investigated on a CHI 660e instrument.

\section{Results and discussion}

The morphology of GO, which is oxidized from nature graphite power by modified Hummers' method, is wrinkle-liked nanosheets, as shown in the inset of Fig. 2a. The general morphology of GO- $g$-HBPE exhibited a great change as shown in the inset of Fig. 2b. The wrinkle-like nanosheet structure is vague, suggesting that the thickness of GO- $g$-HBPE nanosheets is thicker than that of GO, as shown in Fig. 2a and b. This is due to HBPE polymer introduced onto the GO nanosheets. The macro-porous structure was observed in the cross-section of GO- $g$-HBPE membrane after the extraction of PS template (Fig. 2c). This macro-porous structure consists of two parts (ultramacroporous and macro-porous), as shown in Fig. 2d. The ultramacro-porous structure stems from inserted-PS nanoparticles between laminar-like nanosheets, and the macroporous structure depends on the embeded-PS templates onto laminar-like nanosheets (as shown in Fig. S1†). The morphology of the pure GO membrane exhibited a stacked layer, but the stacked layer of the GO membrane is expanded by PS templates, which can be observed in the cross-section of MGO membrane (as shown in Fig. $\mathrm{S} 2 \dagger$ ).

XPS (Fig. 3a) was performed to investigate the detailed chemical bonds formation on GO plates before and after grafting HBPE. A considerable degree of oxidization was obtained corresponding to carbon atoms in different oxygen 

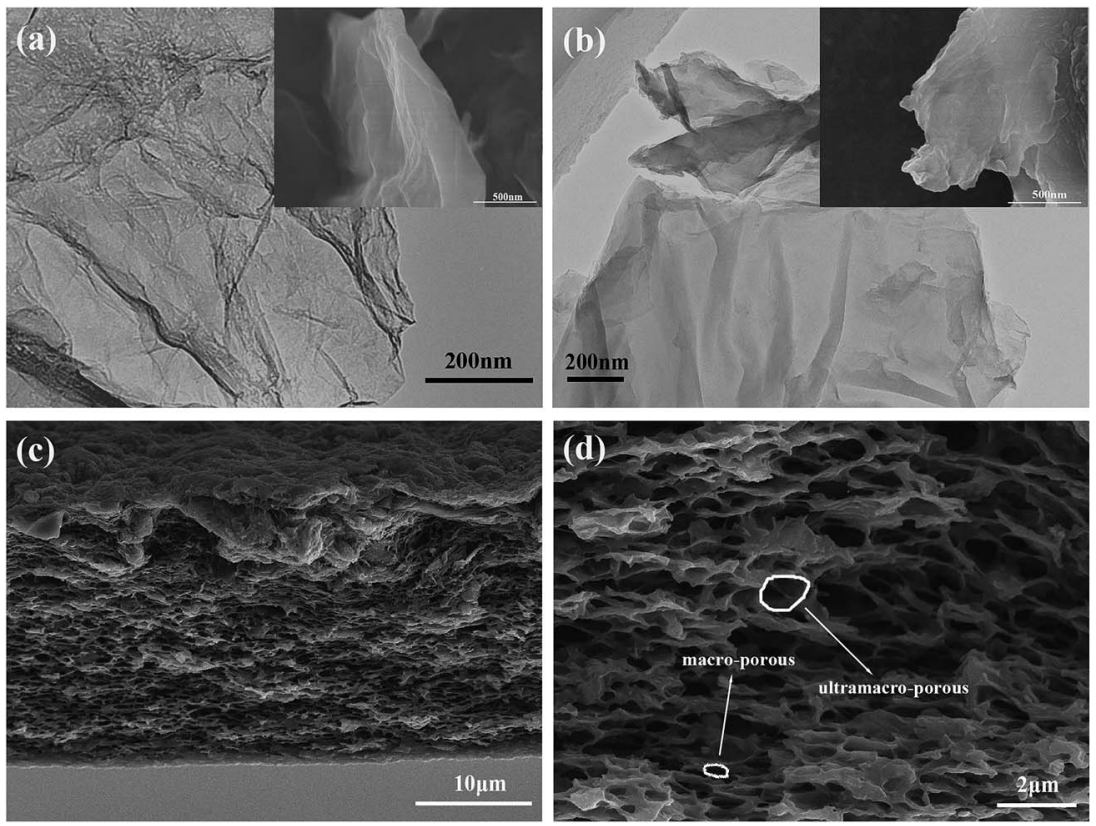

Fig. 2 Morphology of the prepared samples and macro-porous membrane: the TEM image of (a) GO (inset is SEM image) and (b) GO-g-HBPE (inset is SEM image), (c) the SEM images of low-magnified and (d) high-magnified cross-section of GO-g-HBPE free-standing macro-porous membrane.

groups: hydroxyl groups $(-\mathrm{OH})(285.8 \pm 0.2 \mathrm{eV})$, epoxy groups $(286.5 \pm 0.2 \mathrm{eV})$, carbonyl groups $(\mathrm{C}=\mathrm{O})(287.2 \pm 0.2 \mathrm{eV})$ and carboxyl groups $(\mathrm{O}-\mathrm{C}=\mathrm{O})(288.8 \pm 0.2 \mathrm{eV}){ }^{29,30}$ The concentration of $-\mathrm{OH}$ groups strongly increased after grafting HBPE, which was attributed to multi-end $-\mathrm{OH}$ groups in HBPE. However, the epoxy groups and $\mathrm{C}=\mathrm{O}$ decrease significantly, owing to decomposition during the reaction at high temperatures. Moreover, this point was further confirmed by the lower atomic concentration of O (34\%) in GO- $g$-HBPE than that of GO (45\%), as shown in Table S1, $\dagger$ and another reason for the decreased concentration of $\mathrm{O}$ was the high concentration of $-\mathrm{CH}_{2}$ polymer chains in HBPE.

FTIR spectroscopy was used to characterize the presence of GO and GO- $g$-HBPE, as shown in Fig. 3b. HBPE was confirmed by $-\mathrm{OH}\left(\sim 3400 \mathrm{~cm}^{-1}\right),-\mathrm{CH}_{3}\left(2920 \mathrm{~cm}^{-1}\right)-\mathrm{CH}_{2}\left(2870 \mathrm{~cm}^{-1}\right)$, $-\mathrm{CH}\left(1458 \mathrm{~cm}^{-1}\right)$ and $\mathrm{C}-\mathrm{O}-\mathrm{C}\left(1116\right.$ and $\left.1020 \mathrm{~cm}^{-1}\right)$, which can
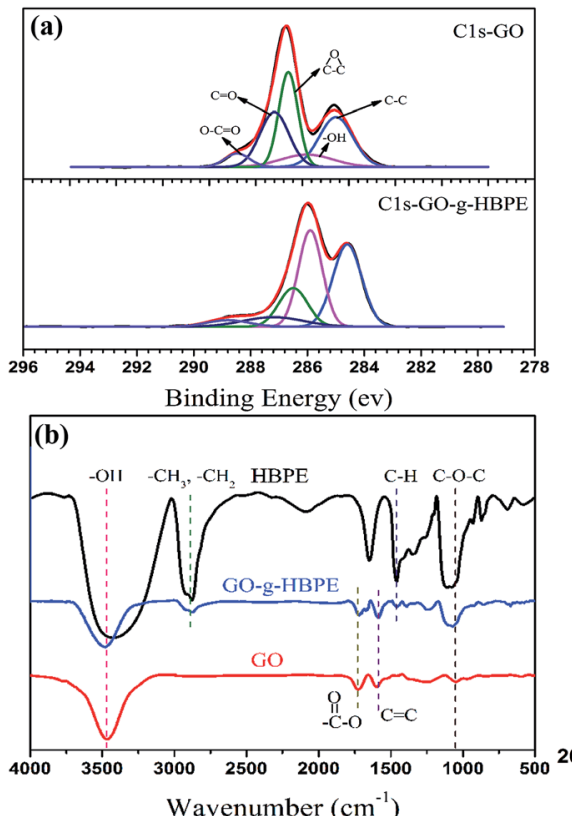

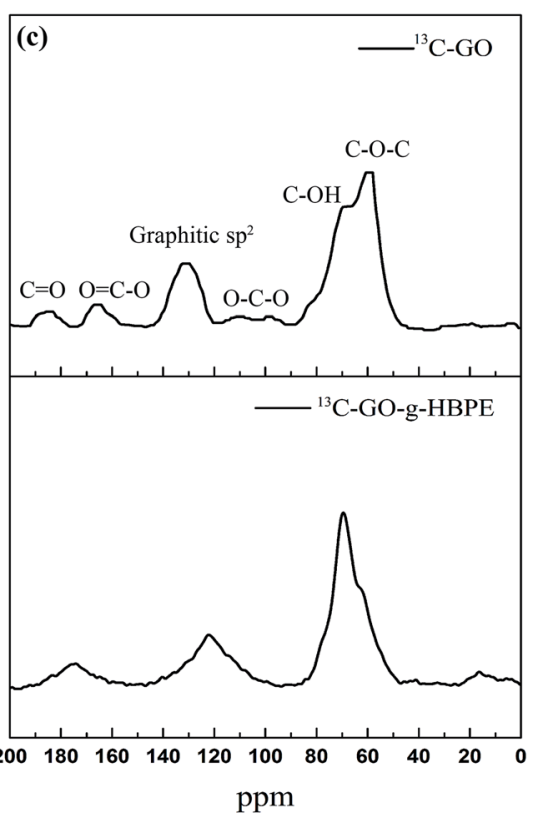

Fig. 3 (a) XPS spectra of C 1s-GO and C 1s-GO-g-HBPE; (b) FTIR spectra of GO and GO-g-HBPE; (c) solid-state ${ }^{13} \mathrm{C}$ NMR spectra of GO and GO$g$-HBPE. 
be observed in Fig. 3b. The chemical structure of HBPE was determined further by ${ }^{1} \mathrm{H}$ and ${ }^{13} \mathrm{C}$ NMR, as shown in Fig. S3. $\dagger$ The characteristic functional groups of $\mathrm{GO}$ were found to correspond to $-\mathrm{OH}\left(\sim 3400 \mathrm{~cm}^{-1}\right), \mathrm{C}=\mathrm{O}\left(\sim 1723 \mathrm{~cm}^{-1}\right), \mathrm{C}-\mathrm{O}-\mathrm{C}$ $\left(\sim 1040 \mathrm{~cm}^{-1}\right)$. Compared to the peaks with GO, new peaks at $\sim 2870 \mathrm{~cm}^{-1}$ and $\sim 1458 \mathrm{~cm}^{-1}$, which were attributed to methyl and methylene groups $\left(-\mathrm{CH}_{3}\right.$ and $\left.-\mathrm{CH}_{2}\right)$, and $\mathrm{C}-\mathrm{H}$ plane blending vibrations, were detected in GO- $g$-HBPE. $\mathrm{O}-\mathrm{C}=\mathrm{O}$ was shifted to $1730 \mathrm{~cm}^{-1}$. Moreover a broad peak at $1200 \mathrm{~cm}^{-1}$ corresponding to $\mathrm{C}-\mathrm{O}-\mathrm{C}$ connected to $\mathrm{C}=\mathrm{O}$ indicates the existence of an ester group. Furthermore, C-O stretching vibration of primary alcohol occurs at $1116 \mathrm{~cm}^{-1}$ and the characteristic $\mathrm{C}-\mathrm{O}-\mathrm{C}$ peak at $\sim 1020 \mathrm{~cm}^{-1}$ related to ether groups increases. The chemical structure of the resulting samples was determined further by solid-state NMR. In the spectra of GO (Fig. 3c). The peaks at 60 and 70 ppm are attributed to $\mathrm{C}-\mathrm{O}-\mathrm{C}$ and $-\mathrm{OH}$ groups, respectively. The resonance at $101 \mathrm{ppm}$ represents lactols $\left(\mathrm{O}-\mathrm{C}\left(\mathrm{sp}^{3}\right)-\mathrm{O}\right)$. The peak at $130 \mathrm{ppm}$ belongs to the un-oxidized graphitic $\mathrm{sp}^{2}$ carbons of graphene network. $\mathrm{O}-\mathrm{C}=\mathrm{O}$ and $\mathrm{C}=\mathrm{O}$ groups presumably appears at 164 and $190 \mathrm{ppm}$, respectively. ${ }^{31-33}$ However, in the case of GO- $g$ $\mathrm{HBPE}$, the intensity of $-\mathrm{OH}$ groups at $70 \mathrm{ppm}$ greatly increases, and the results are coincident with the XPS spectrum (Fig. 3a). The peaks of $\mathrm{O}-\mathrm{C}\left(\mathrm{sp}^{3}\right)-\mathrm{O}$ and $\mathrm{C}=\mathrm{O}$ groups disappear instead of broadening the peaks of graphitic $\mathrm{sp}^{2}$ carbons. This relates to thermal decomposition of these groups during the grafting reaction, resulting in a relatively high integrated graphitic structure.

Fig. 4 displays the crystalline structures of GO and GO-gHBPE observed using XRD. The XRD patterns of GO show the main peaks at $10.1^{\circ}$, which determine that the interlay space is $0.87 \mathrm{~nm}$. A broad characteristic peak at $21.5^{\circ}$ was attributed to GO- $g$-HBPE, corresponding to interlayer space of $0.41 \mathrm{~nm}$. The decreased interlayer space depends on the decomposition of $\mathrm{C}-\mathrm{O}-\mathrm{C}$ and $\mathrm{C}=\mathrm{O}$ groups in the $\mathrm{GO}$ nanosheets. The broad peaks indicate that GO- $g$-HBPE is in a disordered state. ${ }^{34}$ This can be confirmed from Raman spectrum, as shown in Fig. S4. $\dagger$

The thermal stability of GO and GO- $g$-HBPE was evaluated under a nitrogen atmosphere from $50{ }^{\circ} \mathrm{C}$ to $800{ }^{\circ} \mathrm{C}$ by TGA (Fig. 5a). A large weight loss $(\sim 30 \%)$ occurs with an onset

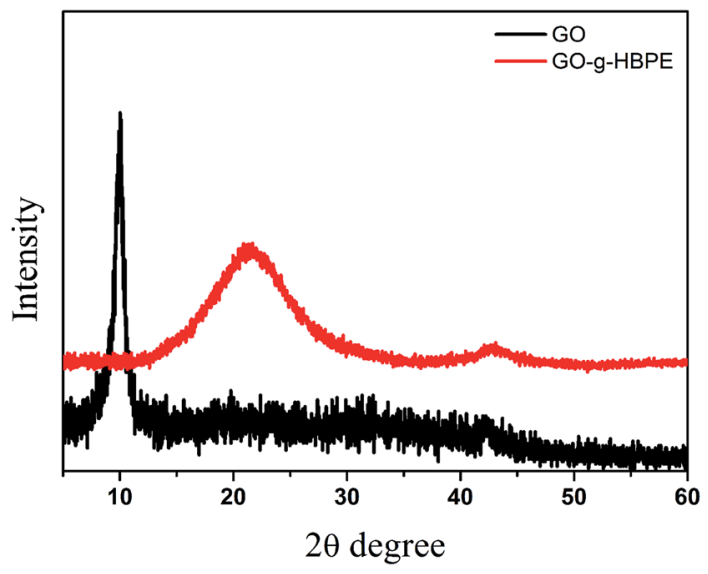

Fig. 4 XRD patterns of GO and GO-g-HBPE. temperature of $200{ }^{\circ} \mathrm{C}$, which means the $\mathrm{GO}$ is thermally unstable, due to the high concentration of water in GO and the thermal sensitive groups (epoxy, lactols and carbonyl) that disrupt the hexagonal carbon basal planes, resulting in a weakening of the van der Waals forces between layers. ${ }^{35,36} \mathrm{In}$ contrast, no evidence for weight loss of GO- $g$-HBPE was observed before $200{ }^{\circ} \mathrm{C}$. This suggests that the thermal stability is enhanced significantly by the introduction of HBPE polymer onto GO. This was attributed to the strong inter- and intramolecular interactions. The thermal dimensional stability was determined further by the calculated dimensional changes after heating the separators to $200{ }^{\circ} \mathrm{C}$ for $0.5 \mathrm{~h}$ (see Fig. $5 \mathrm{~b}$ and c). As shown in Fig. S5†, although the pure GO and MGO membranes have no evident dimensional changes, both can succumb to thermal decomposition, and this result corresponds to TGA. Fig. $5 \mathrm{~b}$ and $\mathrm{c}$ show that the GO- $g$-HBPE separator shows superior thermal dimensional stability than the PP separator. This not only depends on the thermal robustness of the GO- $g$-HBPE, but also on the non-polymeric binder used in the membrane.

The electrochemical stability was tested by linear sweep voltammetry at $5 \mathrm{mV} \mathrm{s}^{-1}$ to determine if the GO- $g$-HBPE separator was suitable for Li-ion batteries. As shown in Fig. S6, $\uparrow$ the current flow of MGO separator was only steady before $4 \mathrm{~V}$ owing to electrochemical active groups, such as epoxy, lactols and carbonyl, benefitting from the stacked layer structure, and the pure GO separator showed a voltage-tolerance of $4.3 \mathrm{~V}$, as shown in Fig. 6a. The current flow is increased significantly to $4.5 \mathrm{~V}$ for the PP separator, which indicates electrochemical decomposition. In the case of the GO- $g$-HBPE separator, no evidence of
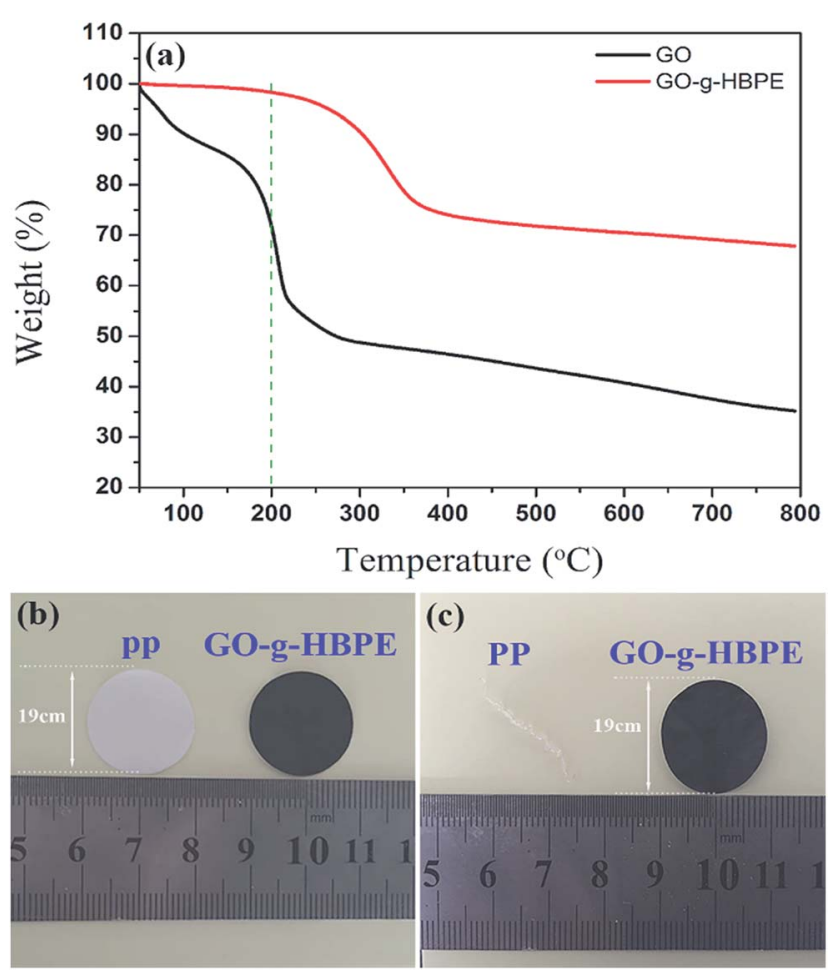

Fig. 5 (a) TGA curves of GO and GO-g-HBPE; photographs of the PP and GO-g-HBPE separators (b) before and (c) after heating to $200{ }^{\circ} \mathrm{C}$ for $0.5 \mathrm{~h}$ 

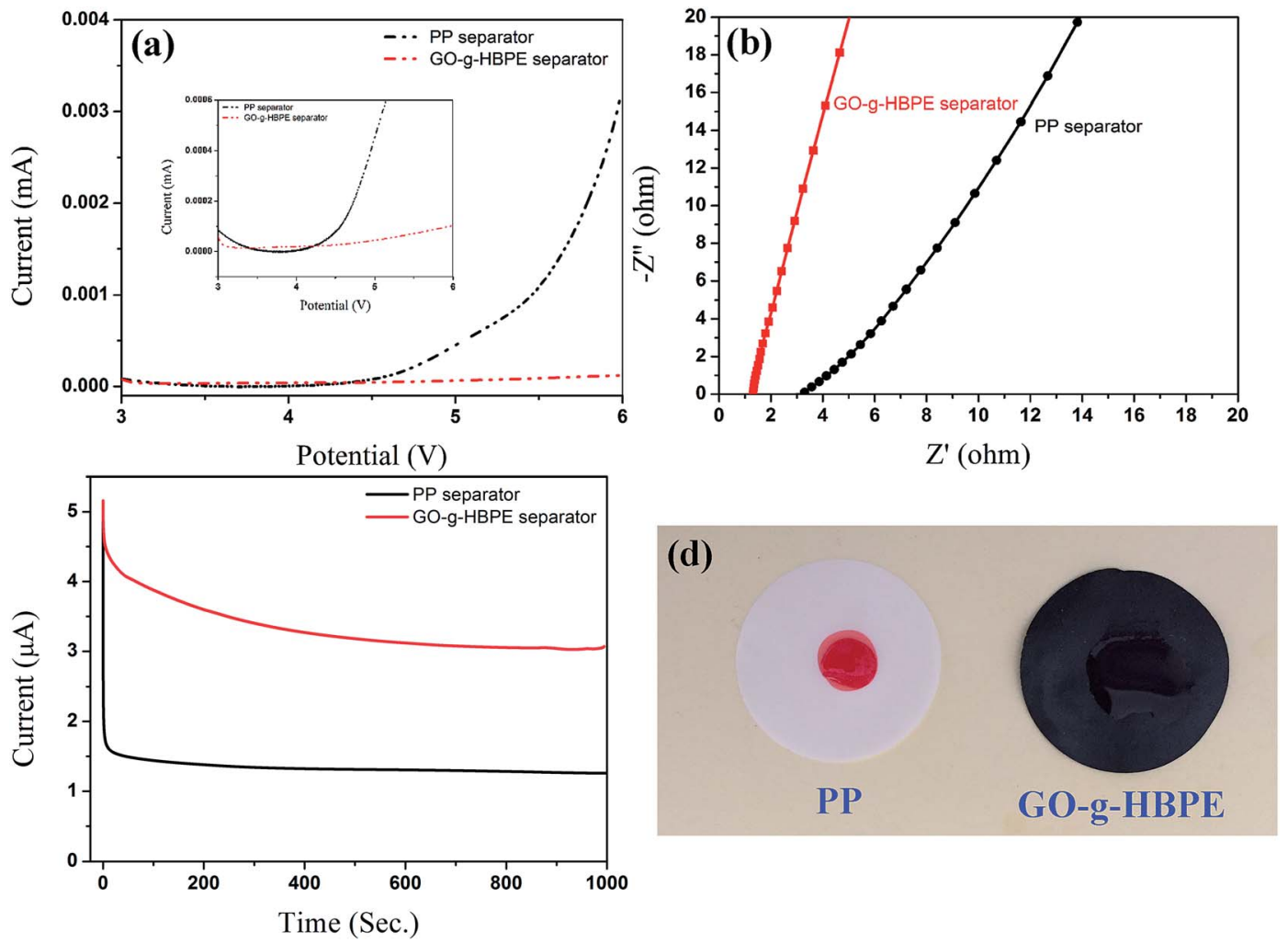

Fig. 6 (a) Linear sweep voltammograms of PP and GO-g-HBPE separator; (b) AC impedance spectra of PP and GO-g-HBPE separator; (c) chronoamperometry profiles of the PP and GO-g-HBPE separator under a step potential of $10 \mathrm{mV}$; (d) photograph of electrolyte infiltration on the separator (the electrolyte contained methyl orange).

current flow was observed before $5 \mathrm{~V}$. This indicates that the separator based on GO-g-HBPE exhibited superior electrochemical stability than the PP separator, resulting from the lower concentration of electrochemical active groups (epoxy, lactols and carbonyl).

In order to investigate the ionic conductivity of the separator based on PP and GO-g-HBPE, which determines the applicability of the separators for Li-ion batteries. A cell type of SS// separator//SS was used to evaluate $R_{\mathrm{b}}$ of both separators by the AC impedance. The calculated ionic conductivity for these separators was $0.47 \mathrm{mS} \mathrm{cm}^{-1}$ and $1.7 \mathrm{mS} \mathrm{cm}^{-1}$, which is much higher than that of the pure $\mathrm{GO}\left(0.07 \mathrm{mS} \mathrm{cm}^{-1}\right)$ and MGO $(0.28$ $\mathrm{mS} \mathrm{cm}{ }^{-1}$ ) separator, as shown in Table $\mathrm{S} 2 \dagger$ obtained from the value of $R_{\mathrm{b}}$ (Fig. 6b). This indicates that the GO-g-HBPE separator is suitable for high-power Li-ion batteries. Furthermore, the number of $t_{+}$was tested by chronoamperometry using Li foil as both electrodes. The specific $t_{+}$numbers for PP and GO- $g_{-}$ HBPE separators are 0.26 and 0.58 , as obtained from the value of initial current to the equilibrium current in Fig. 6c. However, the $t_{+}$of pure GO and MGO separator was only 0.11 and 0.18 , respectively. These remarkable ionic conductivities and relatively high $t_{+}$numbers are due mainly to the high porosity and superior liquid electrolyte uptake. The wetting characteristics of the electrolyte on the separators is shown in Fig. 6d. The electrolyte was formed dropwise on the PP separator but spread over the GO-g-HBPE separator. This suggests that the GO-g-HBPE has better electrolyte compatibility owing to the multi ether groups in the HBPE chain. The porosity and liquid electrolyte uptake of the separators can be observed in Table S2. $\dagger$ Although the porosity of MGO and GO-g-HBPE membrane are close $(55 \%$ for MGO, $58 \%$ for GO- $g$-HBPE), the electrolyte uptake of GO- $g$-HBPE is much higher than that of MGO (68\% for MGO; 158 for GO-gHBPE). This suggests that the membrane of GO-g-HBPE is more suitable as a separator for Li-ion batteries than that of MGO. This is because the electrolyte uptake is determined by the membrane morphology and electrolyte absorptivity (swelling property). The macropores morphology provides volume to retain the electrolyte, and the electrolyte uptake of MGO and pure GO separator is well supported. On the other hand, the rigid hexagonal carbon skeleton is difficult to swell by the electrolyte. However, HBPE with a flexible polymer chain is easy swelling and the ether group assists in the retention of electrolyte, which causes the high electrolyte uptake of the GO-gHBPE separator.

We investigated and discussed the electrochemical performance of the cells consisting of electrolyte-soaked PP and GO- $g$ HBPE separators sandwiched between two electrodes that used $\mathrm{LiFePO}_{4}$ as a cathode, lithium foil as a counter and reference electrode. Fig. 7a shows the first charge-discharge curves of the separators based on PP and GO-g-HBPE at 0.1C $\left(25.50 \mathrm{~mA} \mathrm{~g}^{-1}\right)$ in voltage range from 2.75 to $4.2 \mathrm{~V}$. The typical electrochemical pseudoplateaus for $\mathrm{LiFePO}_{4}(3.5 \mathrm{~V}$ for charge, $3.4 \mathrm{~V}$ for discharge) can be observed in Fig. 7a. This depends on the oxidation and reduction potential for $\mathrm{LiFePO}_{4} \cdot{ }^{37-39}$ The 

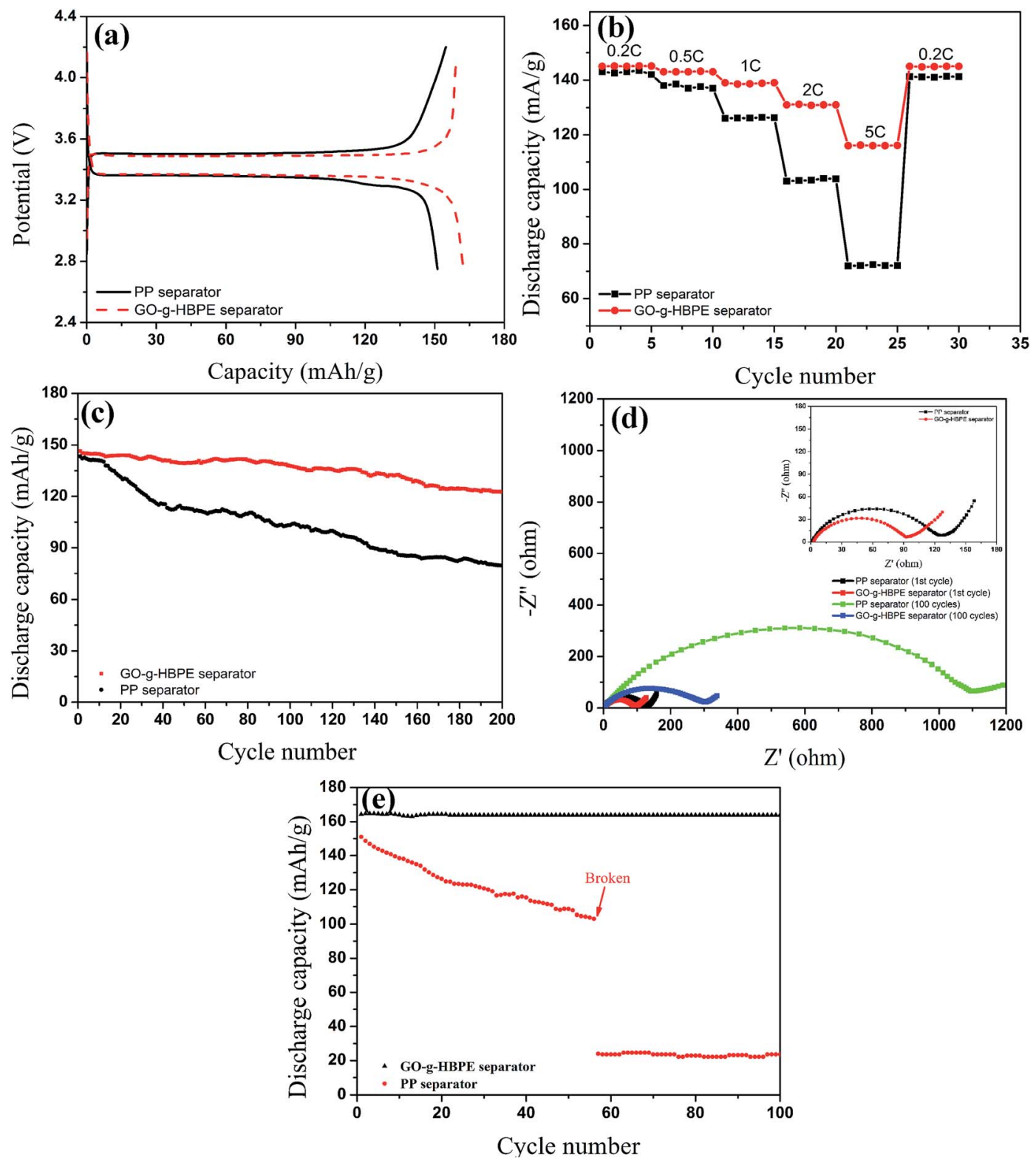

Fig. 7 Electrochemical performance of the $\mathrm{LiFePO}_{4}$ half cells assembled with PP and GO-g-HBPE separators; lithium foil served as both the counter and reference electrodes: (a) the first charge-discharge curves; (b) rate behaviour; (c) cycling performance; (d) $1^{\text {st }}$ and $100^{\text {th }}$ cycle $A C$ impedance spectra of the GO-g-HBPE separator (the inset provides the $1^{\text {st }}$ - and $100^{\text {th }}$-cycle AC impedance spectra of the PP separator); (e) charge-discharge performance at an elevated temperature of $80^{\circ} \mathrm{C}$.

discharge capacity of GO- $g$-HBPE based on the separator is 160

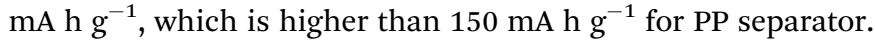
Moreover, the polarization value for GO-g-HBPE separator ( 0.11 $\mathrm{V})$, calculated from the difference in the charge and discharge plateaus, is lower than that of the PP separator $(0.14 \mathrm{~V})$. This indicates that the GO-g-HBPE separator exhibits lower internal resistance than the PP counterpart. The reasons are mainly the excellent liquid electrolyte uptake for GO- $g$-HBPE separator and its macro-porous structure, which provides high ionic conductivity and a larger $t_{+}$number than that of the PP counterpart. On the contrary, there is a valley at the end of the first discharge plateau and a peak at the beginning of the charge profile for the cell with the pure GO separator, which is an indication of a large polarization. The charge curve for the cell based on the MGO separator, as shown in the red arrow labeled in Fig. S7, $\dagger$ indicates poor electrochemical stability. This is because the stacked layer of the pure GO separator impedes the ionic transportation and makes it to be saturated by the liquid electrolyte, which further increases the polarization of the batteries. The electrochemical instability was attributed to the decomposition of electrochemical-active groups in GO. The result is consistent with the property of electrochemical stability of the MGO separator (Fig. S6 $\dagger$ ). The rate behavior for the cells employing the PP separator and GO- $g$-HBPE tested at various current densities (0.2C: $51.0 \mathrm{~mA} \mathrm{~g}^{-1}, 0.5 \mathrm{C}: 127.5 \mathrm{~mA} \mathrm{~g}^{-1}, 1 \mathrm{C}: 255.0 \mathrm{~mA}$ $\mathrm{g}^{-1}, 2 \mathrm{C}: 510.0 \mathrm{~mA} \mathrm{~g}^{-1}, 5 \mathrm{C}: 1275.0 \mathrm{~mA} \mathrm{~g}^{-1}$ ) is displayed in 
Fig. 7b. Fig. 7b shows that the discharge capacity of the cell using the PP separator decreases significantly from $143 \mathrm{~mA} \mathrm{~g}^{-1}$ at $0.2 \mathrm{C}$ to $70 \mathrm{~mA} \mathrm{~g}^{-1}$ at $5 \mathrm{C}$; in the case of the GO- $g$-HBPE separator, the capacity is kept at $145 \mathrm{~mA} \mathrm{~g}^{-1}$ for $0.2 \mathrm{C}$ and 110 $\mathrm{mA} \mathrm{g}^{-1}$ for $5 \mathrm{C}$. The capacity retention for each is $48 \%$ and $76 \%$, respectively. This suggests that the cell based on GO- $g$-HBPE separator shows good rate capability. To evaluate cycling stability of batteries for commercial applications, the cycling performance of the cells with both separators was measured on a LAND cycle system at $0.2 \mathrm{C}$ for 200 cycles. As shown in Fig. 7c, the cell assembled with the GO- $g$-HBPE separator showed better cycling stability and initial capacity than that of the cell using the PP separator. Moreover, the capacity retention after 200 cycles for the cell equipped with the GO- $g$-HBPE separator was $84 \%$ higher than the $47 \%$ for the cell based on the PP separator. The obtained results were attributed to a stable solid electrolyte interface layer (SEI). Furthermore, this stable SEI layer provides steady ionic transportation, resulting in good cycling performance. ${ }^{40}$ The variation of the cell impedance during cycling was confirmed by examining the resistance changes of the cell based on the both separators after the $1^{\text {st }}$ and $100^{\text {th }}$ cycles. The semicircle at the high frequency represents the charge transference resistance corresponding to migration of $\mathrm{Li}$ ions between the electrode and electrolyte interface; the straight slopping line is accompanied by the diffusion of Li ions in the active material of the electrode. ${ }^{\mathbf{4 1 4 2}}$ Fig. $7 d$ shows that the charge transference resistance after the $1^{\text {st }}$ cycle of the cell using GO- $g$-HBPE separator was $90 \mathrm{ohm}$, which is slightly lower than that of the PP separator (120 ohm). The resistance after 100 cycles for the cell with the PP separator intensively increased to $500 \mathrm{ohm}$ (380 ohm for difference of transference resistance), whereas that of the cell based on the GO- $g$-HBPE separator displayed $150 \mathrm{ohm} \mathrm{(60} \mathrm{ohm} \mathrm{for} \mathrm{difference} \mathrm{of} \mathrm{transference}$ resistance). This indicates that the GO- $g$-HBPE exhibits better interface stability than that of the PP separator, which is coincident with the cycling performance of the batteries. To simulate the actual working conditions of batteries, the cycling performance was further examined at an elevated temperature of $80{ }^{\circ} \mathrm{C}$. As shown in Fig. 7e, the cell equipped with the GO- $g$ HBPE separator at $80{ }^{\circ} \mathrm{C}$ showed even better cycling performance than the one at room temperature. This is dependent on the viscosity of the electrolyte. The viscosity of the electrolyte decreases at elevated temperature and at this time, the $\mathrm{Li}^{+}$ion passes rapidly from the macroporous GO- $g$-HBPE, leading to a high performance. In contrast, in the case of PP separator, the discharge capacity decreased significantly at serial cycles, and the performance was lost at 56 cycles. This means that the flexible PP polymer chain can be activated at high temperature, reflecting a high mobility. This could weaken the mechanical performance of the PP separator. In addition, dendritic lithium favors an accelerated electrochemical reaction, further causing the separator to be punctured.

\section{Conclusions}

In summary, a macro-porous GO- $g$-HBPE membrane serving as the separator for Li-ion battery was prepared by a vacuum filtration method, using PS nanoparticles as the hard template. To assist with the HBPE polymer segment, this separator shows excellent electrolyte uptake and ionic conductivity. Moreover, the separator exhibited remarkable thermal resistance after grafting HBPE. These show that the batteries using the GO- $g$ HBPE separator exhibit a much better rate capability, higher discharge capacity and superior capacity retention than the PP separator, highlighting the promising potential applications in high-safety and high-power lithium-ion batteries.

\section{Acknowledgements}

This study is supported by the link project of the National Natural Science Foundation of China and Guangdong Province (No. U1401246), the National Natural Science Foundation of China (Grant No. 51276044), the Science and Technology Program of Guangdong Province of China (Grant No. 2014B010106005, 2015B010135011, 2015A050502047, 2016A020221031), Research Fund of Young Teachers for the Doctoral Program of Higher Education of China (20134420120009), Special Program for Public Interest Research and Capability Construction of Guangdong (2014A010105047), Science and Technology Planning Project of Guangzhou (201707010367) and the Science and Technology Program of Guangzhou City of China (Grant No. 201508030018).

\section{References}

1 P. Arora and Z. J. Zhang, Chem. Rev., 2004, 104, 4419-4462.

2 C. J. Orendorff, Electrochem. Soc. Interface, 2012, 21, 61-65.

3 S. H. Woo, H. W. Lim, S. Jeon, J. J. Travis, S. M. George, S. H. Lee and N. S. Choi, J. Electrochem. Soc., 2013, 160, A2234-A2243.

4 H. Li, Z. Wang, L. Chen and X. Huang, Adv. Mater., 2009, 21, 4593-4607.

5 H. Lee, M. Yanilmaz, O. Toprakci, K. Fu and X. Zhang, Energy Environ. Sci., 2014, 7, 3857-3886.

6 Y. Hu and X. Sun, J. Mater. Chem. A, 2014, 2, 10712-10738.

7 J.-W. Jung, C.-L. Lee, S. Yu and I.-D. Kim, J. Mater. Chem. A, 2016, 4, 703-750.

8 C. J. Orendorff, T. N. Lambert and C. A. Chavez, Adv. Energy Mater., 2013, 3, 314-320.

9 X. C. Xiao, D. Ahn, Z. Y. Liu, J. H. Kim and P. Lu, Electrochem. Commun., 2013, 32, 31-34.

10 D. Fu, B. Luan, S. Argue, M. N. Bureau and I. J. Davidson, J. Power Sources, 2012, 206, 325-333.

11 P. G. Balakrishnan, R. Ramesh and T. P. Kumar, J. Power Sources, 2006, 155, 401-414.

12 J.-A. Choi, S. H. Kim and D.-W. Kim, J. Power Sources, 2010, 195, 6192-6196.

13 M.-H. Ryou, Y. M. Lee, J.-K. Park and J. W. Choi, Adv. Mater., 2011, 23, 3066-3070.

14 W.-K. Shin and D.-W. Kim, J. Power Sources, 2013, 226, 54-60.

15 J. C. Song, M. H. Ryou, B. Son, J. N. Lee, Y. M. Lee, J. W. Choi and J. K. Park, Electrochim. Acta, 2012, 85, 524-530.

16 J.-J. Woo, Z. Zhang, N. L. D. Rago, W. Lu and K. Amine, J. Mater. Chem. A, 2013, 1, 8538-8540. 
17 Y. Zhai, N. Wang, X. Mao, Y. Si, J. Yu, S. S. Al-Deyab, M. ElNewehy and B. Ding, J. Mater. Chem. A, 2014, 2, 14511-14518.

18 J. Zhang, Z. Liu, Q. Kong, C. Zhang, S. Pang, L. Yue and G. Cui, ACS Appl. Mater. Interfaces, 2012, 5, 128-134.

19 T.-H. Cho, M. Tanaka, H. Ohnishi, Y. Kondo, M. Yoshikazu, T. Nakamura and T. Sakai, J. Power Sources, 2010, 195, 42724277.

20 M. Xiong, H. L. Tang, Y. D. Wang and M. Pan, Carbohydr. Polym., 2014, 101, 1140-1146.

21 M. Raja, N. Angulakshmi, S. Thomas, T. P. Kumar and A. M. Stephan, J. Membr. Sci., 2014, 471, 103-109.

22 Y. C. Jung, S. K. Kim, M. S. Kim, J. H. Lee, M. S. Han, D. H. Kim and D. W. Kim, J. Power Sources, 2015, 293, 675683.

23 D. A. Dikin, S. Stankovich, E. J. Zimney, R. D. Piner, G. H. Dommett, G. Evmenenko and R. S. Ruoff, Nature, 2007, 448, 457-460.

24 D. C. Marcano, D. V. Kosynkin, J. M. Berlin, A. Siniskii, Z. Sun, A. Slesarev and J. M. Tour, ACS Nano, 2010, 4, 4806-4814.

25 A. Sunder, R. Hanselmann, H. Frey and R. Mülhaupt, Macromolecules, 1999, 32, 4240-4246.

26 J. Lee, C. K. Hong, S. Choe and S. E. Shim, J. Colloid Interface Sci., 2007, 310, 112-120.

27 H. Liao, H. Hong, H. Zhang and Z. Li, J. Membr. Sci., 2016, 498, 147-157.

28 J. Shi, Y. Xia, Z. Yuan, H. Hu, X. Li, H. Jiang and Z. Liu, J. Mater. Chem. A, 2015, 3, 7006-7013.
29 D.-W. Wang, C. Sun, G. Zhou, F. Li, L. Wen, B. C. Donose and I. R. Gentle, J. Mater. Chem. A, 2013, 1, 3607-3612.

30 Q. Zeng, X. Leng, K.-H. Wu, I. R. Gentle and D.-W. Wang, Carbon, 2015, 93, 611-619.

31 S. Stankovich, D. A. Dikin, R. D. Piner, K. A. Kohlhaas, A. Kleinhammes, Y. Jia and R. S. Ruoff, Carbon, 2007, 45, 1558-1565.

32 W. Cai, R. D. Piner, F. J. Stadermann, S. Park, M. A. Shaibat, Y. Ishii and J. An, Science, 2008, 321, 1815-1817.

33 W. Gao, L. B. Alemany, L. Ci and P. M. Ajayan, Nat. Chem., 2009, 1, 403-408.

34 K.-W. Park and J. H. Jung, J. Power Sources, 2012, 199, 379385.

35 J. Shen, Y. Hu, M. Shi, X. Lu, C. Qin, C. Li and M. Ye, Chem. Mater., 2009, 21, 3514-3520.

36 E. Yoo, J. Kim, E. Hosono, H. Zhou, T. Kudo and I. Honma, Nano Lett., 2008, 8, 2277-2282.

37 J. Zhang, L. Yue, Q. Kong, Z. Liu, X. Zhou, C. Zhang and Y. Duan, Sci. Rep., 2014, 4, 3935.

38 A. Yamada, S. C. Chung and K. Hinokuma, J. Electrochem. Soc., 2001, 148, A224-A229.

39 C. Delmas, M. Maccario, L. Croguennec, F. L. Gras and F. Weill, Nat. Mater., 2008, 7, 665-671.

40 L. Pan, H. Wang, C. Wu, C. Liao and L. Li, ACS Appl. Mater. Interfaces, 2015, 7, 16003-16010.

41 Q. J. Wang, W. L. Song, L. Z. Fan and Q. Shi, J. Power Sources, 2015, 279, 405-412.

42 S. Hu, S. Lin, Y. Tu, J. Hu, Y. Wu, G. Liu and T. Jiang, J. Mater. Chem. A, 2016, 4, 3513-3526. 